\title{
Dental students benefit from engaging with refugees
}

Dental students at Peninsula Dental School, the University of Plymouth read with interest the advocacy guide published in 2020 by the FDI World Dental Federation entitled Promoting oral health for refugees. ${ }^{1}$

E. Stylianou, E. Pheasant, F. March, M. Paisi and R. Witton wrote to the $B D J$ : 'We agree that quality oral healthcare should become available, accessible, and affordable to all, especially to socially excluded and vulnerable groups, including refugees. Refugees are amongst the most vulnerable groups and have high dental treatment needs. ${ }^{2}$ Their access to dental care in host countries is limited due to affordability of treatment, language barriers, insufficient interpretation, lack of awareness of healthcare systems and their rights to healthcare and negative experiences during dental visits. ${ }^{3}$

Students E. Stylianou, E. Pheasant and F. March engaged with British Red Cross (BRC) in Plymouth as part of their interprofessional engagement module. They provided dental champion training to staff and volunteers and a separate oral health advice workshop to refugees. The dental champion training focused on oral hygiene instruction, fluoride intake and diet advice to empower staff and volunteers.

The students said: 'Through the support of the health charity Well Connected, we were able to provide oral care products to BRC which were given to service users at their discretion. We also provided an oral health resource folder with key information to be used by BRC staff and volunteers. The drop-in interactive workshop allowed us to understand some of the barriers experienced by refugees in navigating the NHS dental system.
'The feedback received demonstrated an increase in the confidence of BRC staff and volunteers when delivering basic oral health messages which in turn will benefit refugee oral health. Being involved in a community outreach programme has highlighted how little we knew about the real barriers that refugees face in accessing dental care and an appreciation of how their priorities differ from ours. The FDI guide is a useful addition to this understanding that will benefit all dental teams.'

The Plymouth students think that this project has furthered their awareness and understanding of the challenges that many patients face and appreciate the opportunity they have been given to explore oral health needs from a community engagement perspective.

'Following this experience, we now feel more confident in treating vulnerable patients with diverse backgrounds and providing personcentred and culturally competent dental care. We recommend that community engagement projects are incorporated into the dental undergraduate curriculum ensuring that students have the opportunity to work with refugees and other vulnerable groups.'

\section{References}

1. Kateeb E, Zaheer K, Fisher J, Ghani A, Williams D, Dartevelle S. Promoting oral health for refugees: an advocacy guide. 1st edition. Geneva: FDI World Dental Federation, 2020

2. Keboa M, Hiles N, Macdonald M. The oral health of refugees and asylum seekers: a scoping review. Global Health 2016; 12: 59.

3. Paisi M, Baines R, Burns L et al. Barriers and facilitators to dental care access among asylum seekers and refugees in highly developed countries: a systematic review. BMC Oral Health 2020; 20: 337. 